$\frac{204}{1-18} c^{\circ} \quad$ DR-1680

September 23, 1970

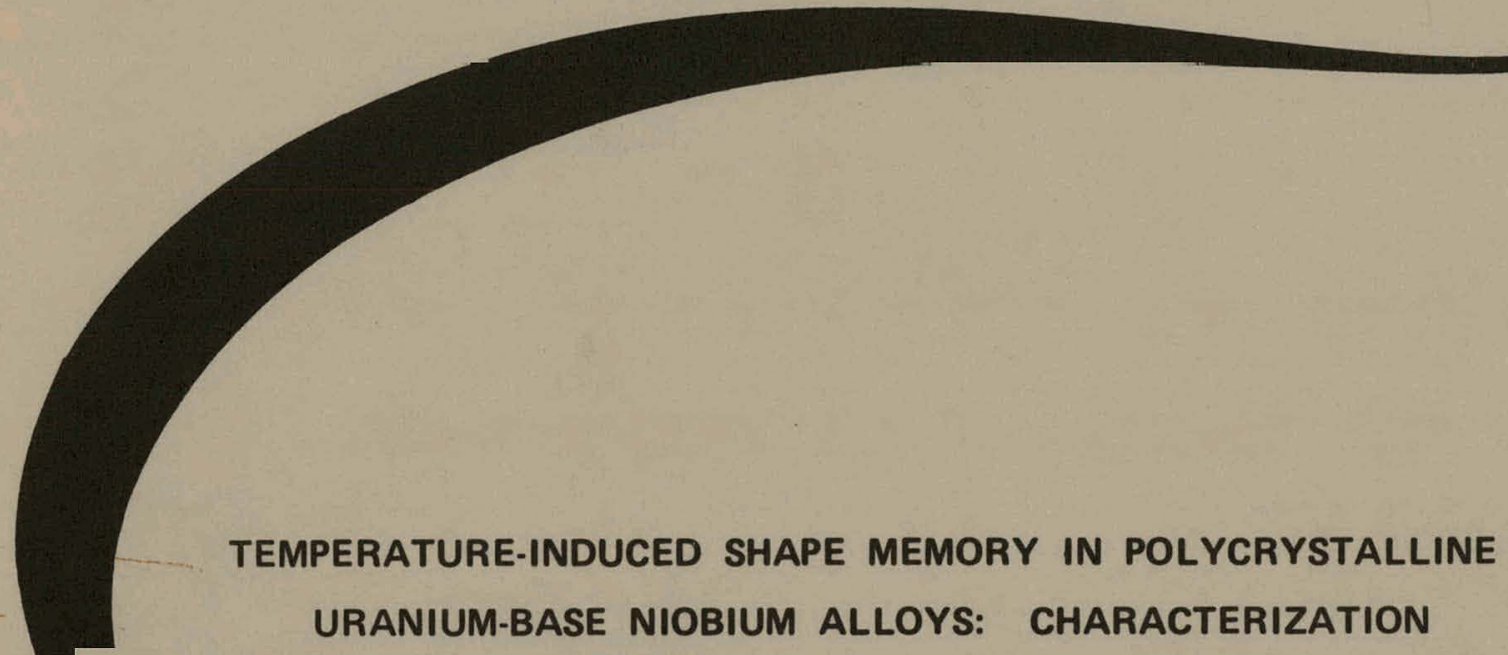

Ross J. Jackson

Wilbur L. Johns
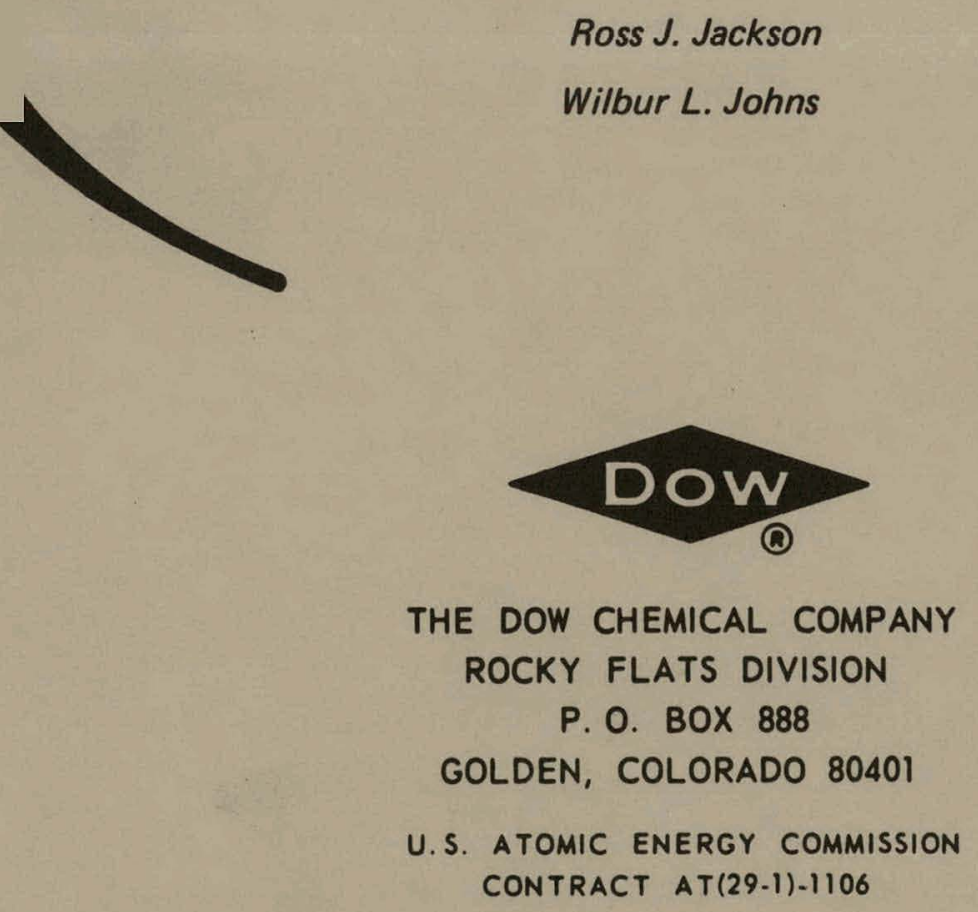

THIS DOCUMENT CONFIRMED AS UNCLASSIFIED

DIVISION OF CLASSIFICATION

BY

GHkahmlamb

DATE $25 / 71$ 


\section{DISCLAIMER}

This report was prepared as an account of work sponsored by an agency of the United States Government. Neither the United States Government nor any agency Thereof, nor any of their employees, makes any warranty, express or implied, or assumes any legal liability or responsibility for the accuracy, completeness, or usefulness of any information, apparatus, product, or process disclosed, or represents that its use would not infringe privately owned rights. Reference herein to any specific commercial product, process, or service by trade name, trademark, manufacturer, or otherwise does not necessarily constitute or imply its endorsement, recommendation, or favoring by the United States Government or any agency thereof. The views and opinions of authors expressed herein do not necessarily state or reflect those of the United States Government or any agency thereof. 


\section{DISCLAIMER}

Portions of this document may be illegible in electronic image products. Images are produced from the best available original document. 


\section{LEGAL NOTICE}

This report was prepared as an account of Government sponsored work. Neither the United States, nor the Commission, nor any person acting on behalf of the Commission:

A. Makes any warranty or representation, expressed or implied, with respect to the accuracy, completeness, or usefulness of the information contained in this report, or that the use of any information, apparatus, method, or process disclosed in this report may not infringe privately owned rights; or

B. Assumes any liabilities with respect to the use of, or for damages resulting from the use of any information, apparatus, method, or process disclosed in this report.

As used in the above, "person acting on behalf of the Commission" includes any employee or contractor of the Commission, or employee of such contractor, to the extent that such employee or contractor of the Commission, or employee of such contractor prepares, disseminates, or provides access to, any information pursuant to his employment or contract with the Commission, or his employment with such contractor.

Printed in the United States of America

Available from

Clearinghouse for Federal Scientific and Technical Information

Naliunal Bureau of Standards, U. S. Department of Commerce

Springfield, Virginia 22151

Price: Printed Copy $\$ 3.00$; Microfiche $\$ 0.65$ 


\section{TEMPERATURE-INDUCED SHAPE MEMORY IN POLYCRYSTALLINE URANIUM-BASE NIOBIUM ALLOYS: CHARACTERIZATION}

Ross J. Jackson

Wilbur L. Johns

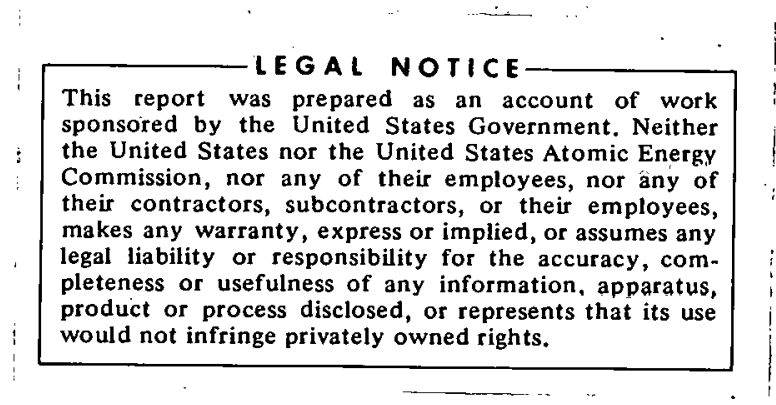

\footnotetext{
THE DOW CHEMICAL COMPANY

ROCKY FLATS DIVISION

P. O. BOX 888

GOLDEN, COLORADO $80401^{\prime \prime}$

Prepured under Contract AT(29-1)-1106

for the

Albuquerque Operations Office

U. S. Atomic Energy Commission
} 
RFP-996 


\section{CONTENTS}

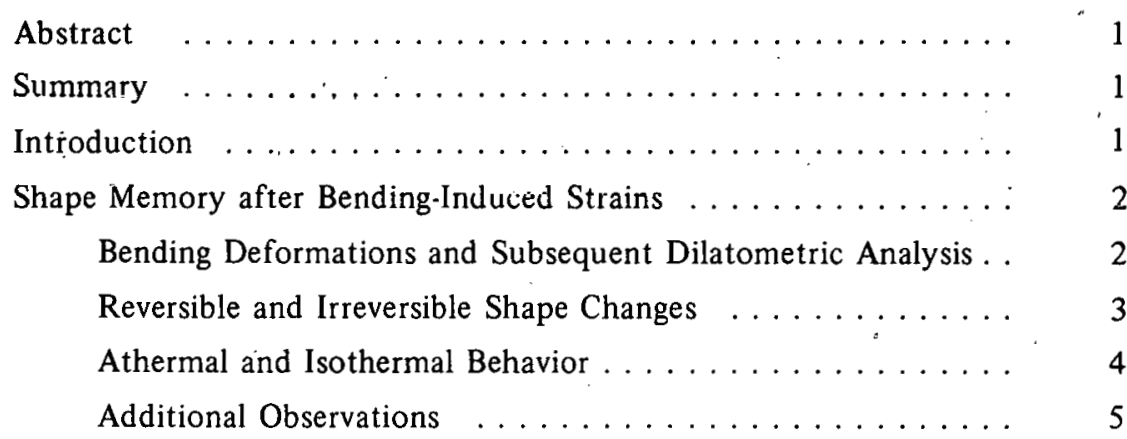

Shape Memory after Uniaxially Induced Tensile

and Compressive Strains; and Rolling Strains .......... 6

References ........................ 7 


\section{$\Lambda$ CKNOWLEDGMENT}

An acknowledgment is extended to Mr. J. F. Boland for first observing the phenomenon characterized in this report. Mr. D. H. Hansen is acknowledged for designing one of the dilatometers and for assisting in some experimental aspects of the study. Thanks are also extended to Mr. S. Beitscher for several stimulating discussions. 


\title{
TEMPERATURE-INDUCED SHAPE MEMORY IN POLYCRYSTALLINE URANIUM-BASE NIOBIUM ALLOYS: CHARACTERIZATION
}

\author{
Ross J. Jackson and Wilbur L. Johns
}

\begin{abstract}
Certain polycrystalline uranium-base niobium alloys undergo unusual shape changes on heating or cooling. The shape changes are athermal and under certain conditions completely reversible. This behavior is referred to as temperature-induced shape memory. The shape changes occur in the compositon range of 6- to 21 -atomic $\% \mathrm{Nb}$ and in the temperature range of $-200^{\circ} \mathrm{C}$ to $+400^{\circ} \mathrm{C}$. For the alloy to exhibit shape memory it must first be cooled rapidly from the gamma region and then subjected to a plastic deformation below $425^{\circ} \mathrm{C}$. This report characterizes the effects of composition, temperature, time at temperature, and types of strain, on the shape memory.
\end{abstract}

\section{SUMMARY}

An unusual internally induced, athermal, and reversible strain behavior has been observed in certain uraniumniobium alloys, This effect occurs in the composition range of 6-to 21 -atomic $\% \mathrm{Nb}$, and reaches a maximum near the U-15 atomic \% $\mathrm{Nb}$ composition. The phenomenon occurs over a temperature range of at least $-200^{\circ} \mathrm{C}$ to $+400^{\circ} \mathrm{C}$. The dimensional change per temperature increment varies as a function of temperature, composition, and cooling rate from the gamma region.

Two conditions necessary for subsequent temperatureinduced shape change are: (a) the sample must be cooled rapidly from the gamma region, and (b) the as-quenched shape must be subjected to a plastic deformation below approximately $425^{\circ} \mathrm{C}$.

Any type of induced plastic strain (e.g., bending, cupping, uniaxial tension, uniaxial compression, and rolling) can give rise to subsequent temperature-induced motion.

The motion on heating above the forming temperature is always in the direction of the as-quenched shape. The motion on cooling below the forming temperature is always in the direction opposite to the as-quenched shape. On the reverse part of the thermal cycle, the motion is always in the direction opposite to that of the forward part of the cycle.

On cycling to subzero temperatures the shape change is dimensionally reversible. On cycling above the forming temperature there is a nonreversible component and a reversible component of shape change. Following the first cycle, the nonreversible component is minimal except at the higher cycling temperatures.

The shape changes, to a first approximation, are athermal in character. However, at the higher cycling temperatures, the shape change shows an isothermal character. Not only does a shape change occur with time, but the magnitude of the shape change on continued cycling is decreased. This effect becomes more easily measured as the temperature and time increase. Holding at $400^{\circ} \mathrm{C}$ for 15 minutes will completely erase any memory and subsequent shape-change behavior.

The memory for the quenched-in shape is remarkable in that cyclic and unusual bending patterns will not destroy the memory for that shape as long as deformations are not too severe.

A macro-residual stress sufficient to cause the observed shape change does not exist in the bend specimens that exhibit temperature-induced strain.

\section{INTRODUCTION}

During formability studies on uranium-base niobium alloys, an unusual temperature-induced shape memory was observed. The U-15 atomic \% Nb alloys, water quenched from the single phase gamma region (e.g., $850^{\circ} \mathrm{C}$ ) and then plastically bent, reverted towards their as-quenched shape on subsequent heating. When the deformed sample was heated and cooled through one temperature cycle, the shape change behavior was partially reversible. Sequence photographs illustrating the temperature-induced shape memory are shown in Figure 1.

The temperature-induced shape memory has not been previously reported for uranium alloys. Somewhat similar, temperature-induced, macroscopic shape changes following deformation have been observed in at least three other binary systems: the In- $\mathrm{Ti}^{1,2}$ $\mathrm{Au}-\mathrm{Cd}^{3,4}$, and $\mathrm{Ti}-\mathrm{Ni}^{5,6}$, systems. The temperatureinduced shape changes occurring in the three systems have been attributed to a single martensitic phase transformation occurring over a relatively small temperature interval. In general, these systems do not show the shape change behavior over the wide range of temperature and compositions that the uranium 


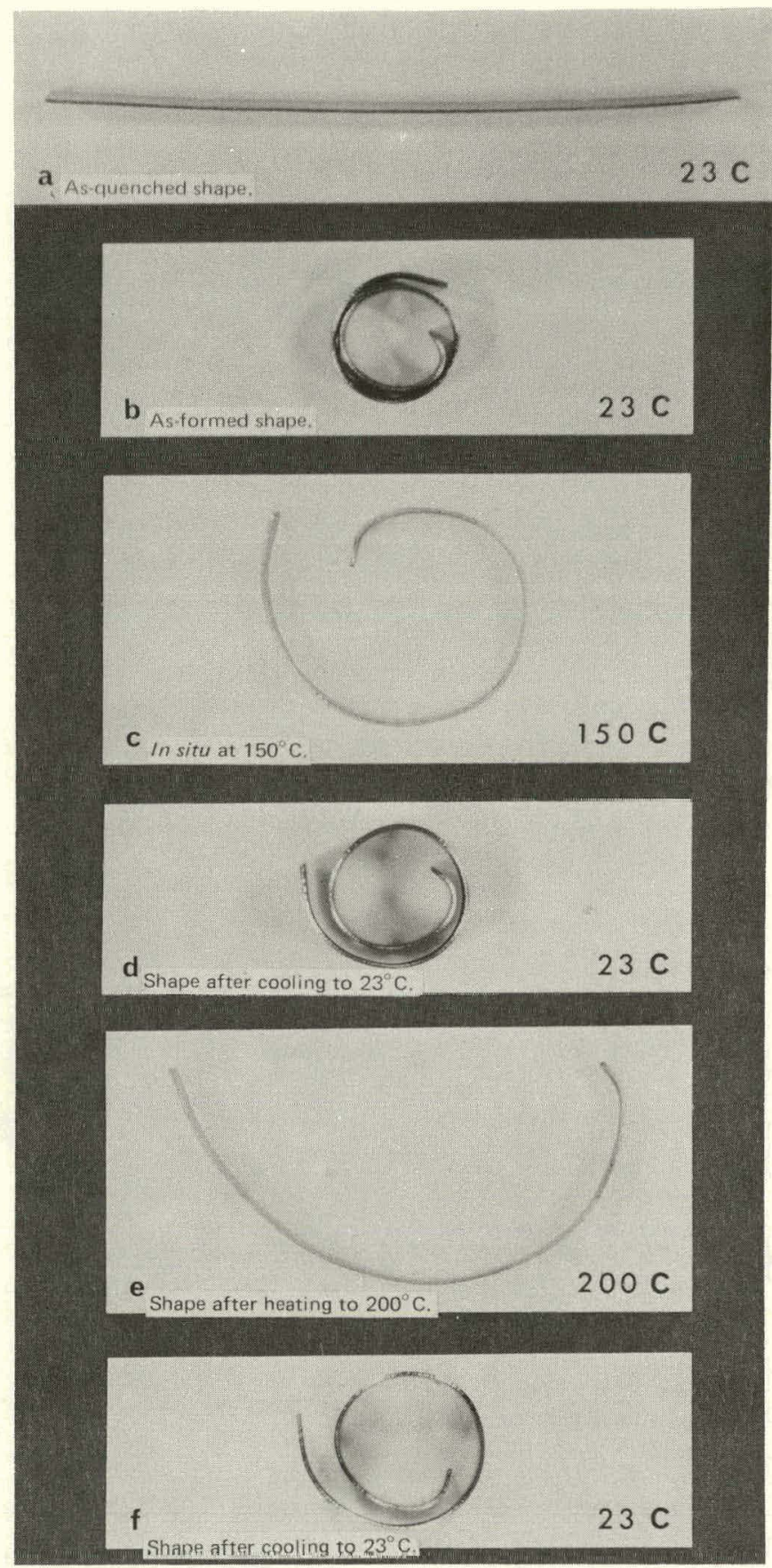

Figure 1. A Sequence of Photographs Illustrating the Temperature-Induced Shape Memory in a U-15 Atomic \% Nb Alloy. If this sample had been heated to $425^{\circ} \mathrm{C}$, it would return to the shape shown in (a), and would retain that shape on subsequent cooling.

alloys do, nor do they exhibit the degrees of reversibility shown by the uranium alloys in the polycrystalline state.

The purity of the U-Nb alloys used, and their preparation and homogenization are described elsewhere. ${ }^{7}$ A small prior grain size (20-40 microns) and somewhat random orientation was obtained by repeated heating into the $\gamma$ region $\left(850^{\circ} \mathrm{C}\right)$ and cross-rolling. The rolling temperature varied from $850^{\circ} \mathrm{C}$ to $550^{\circ} \mathrm{C}$. Samples of various dimensions were machined from the cross-rolled sheet. The machine samples were solution treated 4 hours at $850^{\circ} \mathrm{C}$ in vacuum and water quenched. Water quenching a sample of this size yields a cooling rate of approximately $1000^{\circ} \mathrm{C} / \mathrm{sec}$. The prior $\gamma$ grain size of this material was approximately 100 microns and the grains were equiaxed. The grains were randomly oriented. Prior to deformation, the samples were electropolished in a cold electrolyte to remove the surface film developed on quenching.

\section{SHAPE MEMORY AFTER BENDING-INDUCED STRAINS}

\section{Bending Deformations and Subsequent Dilatometric Analysis:}

Flat, as-quenched specimens of dimensions 2.00-by 0.375 -by 0.61 -inch were plastically deformed by bending a fixed distance at $0^{\circ} \mathrm{C}$ on a three-point bending jig. The bending jig consisted of a base plate to which werc welded two 0.5 -inch rounds whose centers were separated by 1.375 inches. A third 0.5 -inch round was welded to a platen and served as the punch. The $\mathrm{U}-11$ atomic $\% \mathrm{Nb}$, U-15 atomic \% Nb, U-19 atomic \% Nb alloys, and a type 304 stainless steel were bent until the center section of the sample encountered the base of the fixture. For the $\mathrm{U}-9$ atomic $\% \mathrm{Nb}$ alloy, a 1/8-inch shim was placed on the base of the fixture. This shim was necessary because this composition fractured on bending through the larger bend angle.

The bend angle after springback was $105^{\circ}, 95^{\circ}$, $120^{\circ}$, and $88^{\circ}$ for $\mathrm{U}-11$ atomic $\% \mathrm{Nb}, \mathrm{U}-15$ atomic $\% \mathrm{Nb}$, $\mathrm{U}-19$ atomic $\% \mathrm{Nb}$ and 304 stainless steel, respectively. These samples, after bending but prior to springback, had a bend angle of $76^{\circ}$. The difference of the two values is a measure of the springback in the samples.

After deformation, the bend specimen was placed in a simple quenching dilatometer and the amount of temperature-induced motion was measured as a function of temperature and time. The quenching dilatometer consisted of a Sheffield 0-1000 microns, machinist-dial guage, with an extended push rod of 304 stainless steel. The sample holder was of thingauge stainless steel, and was integral with the dial guage. A small guide mark was drilled at the apex of the bend specimen to accept the pointed push rod.

The heating and cooling of the sample was conducted in an isothermal manner. That is, the dilatometer and sample were placed in one bath at temperature $T_{1}$ and held until motion ceased (generally less than 2 minutes). The portable dilatometer including sample was then transferred (less than 5 seconds) to a bath at $T_{2}$ and 
held until the sample ceased moving (again generally less lan 2 minutes). This procedure was usually carried urrough six complete cycles. A silicone oil was used as the heating medium from $0^{\circ} \mathrm{C}$ to $290^{\circ} \mathrm{C}$. Above $290^{\circ} \mathrm{C}$ a vertical muffle furnace with an argon atmosphere was used. Liquid $\mathrm{N}_{2}$ was used for the $-196^{\circ} \mathrm{C}$ bath A dry ice, trichlorethylene slurry was used for the $-70^{\circ} \mathrm{C}$ bath.

The dilatometer yielded the change in bend height $(\Delta \mathrm{h})$ on thermal cycling. The bend height after bending and springback is $h_{0}$ and $h-h_{0}$ is $\Delta h$. The ordinate used in plotting the data is $\Delta h / h_{0}$. The abscissa is the thermal cycle. The value $\Delta h / h_{0}$ was used since it is easily measured and is not measurably influenced by the normal uniform thermal expansion of the material.

\section{Reversible and Irreversible Shape Changes:}

The temperature-induced shape memory was briefly described in the introduction. Figures 2, 3a, 3b, and

Figure 2. Temperature-Induced Shape Change of the U-15 Atomic \% Nb Alloy Following a Bending Deformation. Separate samples were cycled six times between the indicated temperatures.

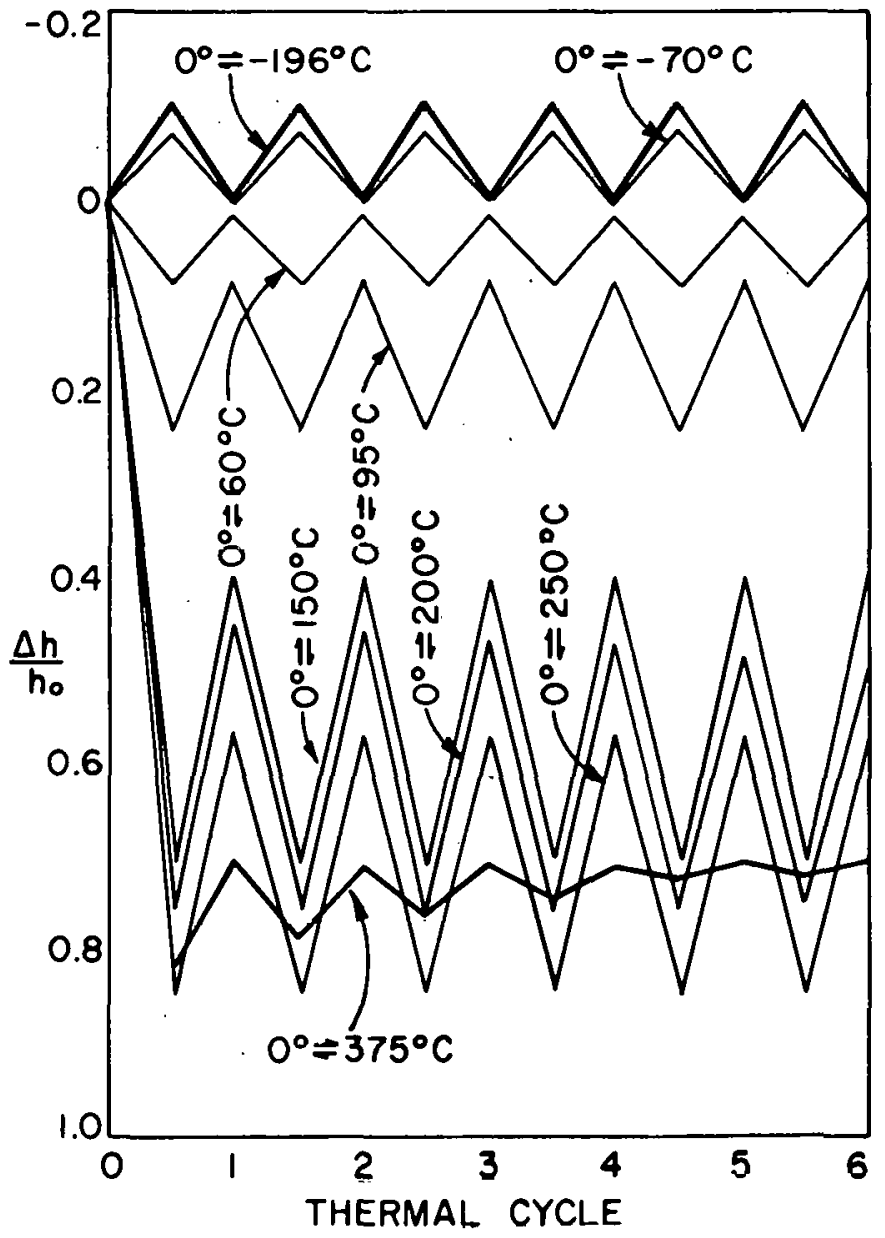

$3 \mathrm{c}$ characterize the temperature-induced shape change following a bending strain for the U-15 atomic $\% \mathrm{Nb}$, $\mathrm{U}-9$ atomic $\% \mathrm{Nb}, \mathrm{U}-11$ atomic $\% \mathrm{Nb}$, and $\mathrm{U}-19$ atomic $\%$ $\mathrm{Nb}$ alloys, respectively. A separate sample was used for each curve. A type 304 stainless steel was given the same treatment as the uranium-niobium alloys. On thermal cycling between $0^{\circ} \mathrm{C}$ and $350^{\circ} \mathrm{C}$ the stainless steel showed no measurable temperature-induced vertical movement.

Figure 3. Temperature-Induced Shape Change of Three Uranium-Niobium Alloys: (a) U-9 Atomic \% Nb, (b) U-11 Atomic \% Nb, and (c) U-19 Atomic \% Nb. Separate samples were cycled six times between the indicated temperatures.
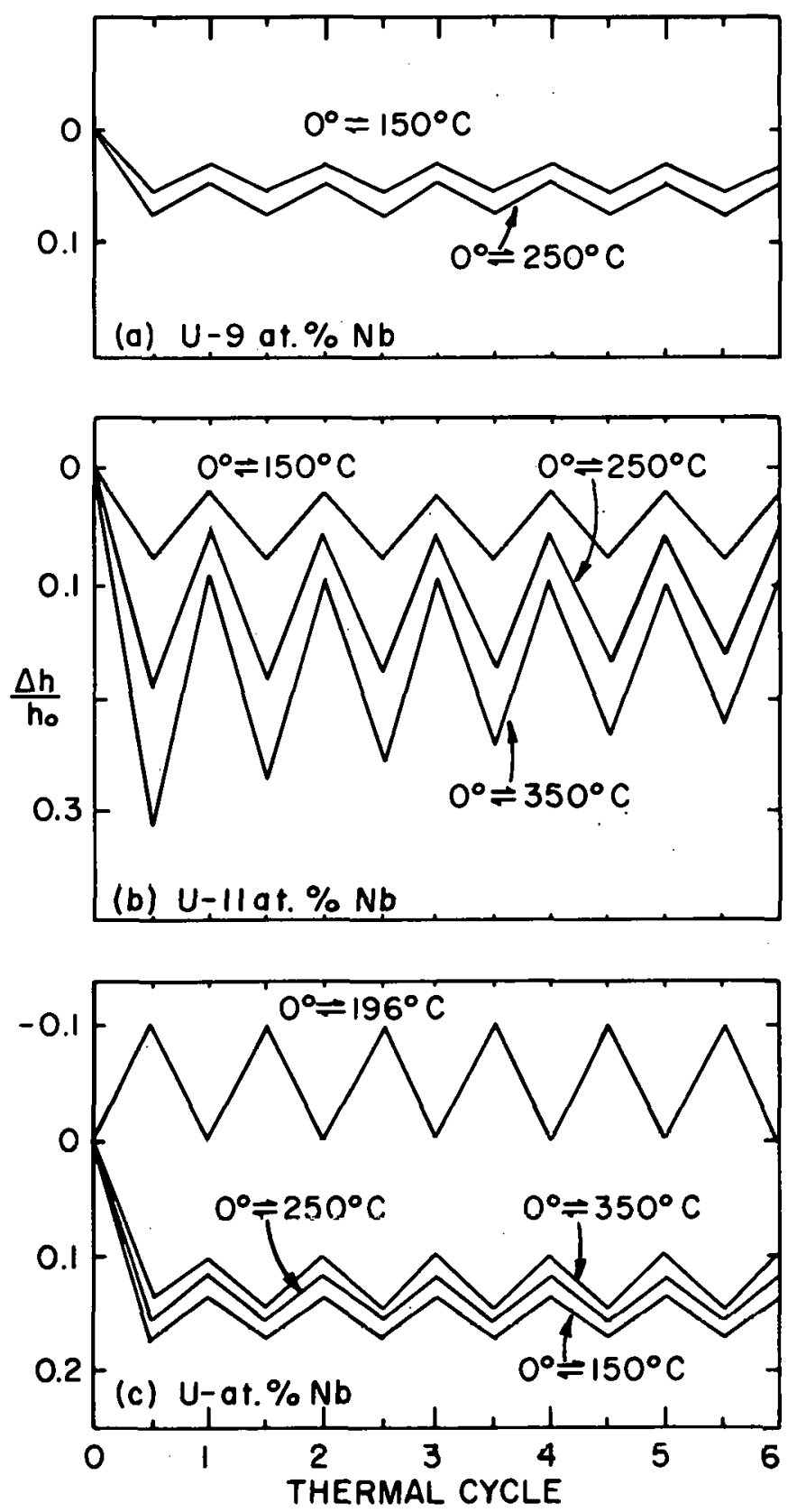
Prior to the dilatometric studies represented in Figures 2 and 3, the sample underwent two necessary operations: (a) the sample was quenched from the gamma region, (e.g., $850^{\circ} \mathrm{C}$ ); and (b) the sample was plastically strained at a temperature below approximately $425^{\circ} \mathrm{C}$ (in this case, $0^{\circ} \mathrm{C}$ ).

Seven salient features are portrayed by the dilatometric results in Figurcs 2 and 3.

1. The internally induced strain occurs over a temperature range of at least $600^{\circ} \mathrm{C}$ (i.e., $-200^{\circ} \mathrm{C}$ to $+400^{\circ} \mathrm{C}$ ).

2. The internally induced strain occurs over a composition range of at least 9- to 19-atomic \% Nb. (Subsequent studies showed that the temperature-induced strain occurs for compositions in the range of G-to 21 atomic \% $\mathrm{Nb}$.)

3. On cooling below the forming temperature, the sample changes shape in an athermal manuer such that the bend height is increased. On reheating to the forming temperature, the sample returns to the initial bend height, $h_{0}$. Therefore, the shape change is dimensionally reversible on thermal cycling below the forming temperature.

4. On heating above the forming temperature, the sample changes shape in an athermal manner such that the bend height is decreased (as-quenched shape). On returning to the forming temperature, the bend height increased (as-tormed shape); but the sample does not attain the initial bend height value. Thus, on the first thermal cycle above the forming temperature, there ale reversiblc and irreversible conmpnents of shape change.

5. On continued temperature cycling above the forming temperature the sample changes shape in a nearreversible manner as long as the upper temperature in feature 4 (above) is not exceeded. Also, the upper temperature must be less than approximately $275^{\circ} \mathrm{C}$ for the change to be near-reversiblc.

6. At the higher cycling temperatures (e.g., $375^{\circ} \mathrm{C}$ ), thcrc is an irreversible component on each thermal cycle, such that the reversible component diminishes to zero on continued thermal cycling.

7. The ninhium content has a strongeffect on the magnitude of shape change. For the data presented, the magnitude of shape change is largest for the U-15 atomic $\% \mathrm{Nb}$ and smallest for U.9 atomic $\% \mathrm{Nb}$ alloy. Likewise, the dimensional change per temperature increment varies with composition. Examples of this are: (a) for the $\mathrm{U}-11$ atomic $\% \mathrm{Nb}$ alloy, the reversible and irreversible components increase in a linear manner with temperature; (b) for the U-15 atomic $\% \mathrm{Nb}$ alloy, the dimensional change per temperature increment reaches a large-valued maximum in the vicinity of $110^{\circ} \mathrm{C}$; and (c) for the $\mathrm{U}-19$ atomic $\% \mathrm{Nb}$ alloy, the dimensional change reaches a maximum below $150^{\circ} \mathrm{C}$ and is nonexistent above this temperature.

\section{Athermal and Isothermal Behavior:}

Thermocouples were embedded near the hend radius in all the samples. Plots of bend height changes, $\Delta h$, versus sample tempcrature, showed, to a first approximation, that sample motion ceased when the bath temperature was reached. Thus, to a first approximation, the tempcrature-induced motion is a function of temperature and not time at temperature (i.e., it is athermal in character).

Time at temperature, however, does have an effect on the shape change behavior. Figure 4 shows the temperatureinduced strain of the $\mathrm{U} \cdot 15$ atomic \% $\mathrm{Nb}$ alloy subjected to isothermal holds at $150^{\circ} \mathrm{C}$ and $250^{\circ} \mathrm{C}$. The isothermal holds were midway of the first cycle. The remaining cycles followed the normal procedure. Thus, upon isothermal holding a shape change occurs that reduces

Figure 4. Temperature-Induced Shape Change of the U-i5 Atomic \% $\mathrm{Nb}$ Alloy after Isothermal Holds at $150^{\circ} \mathrm{C}$ and $250^{\circ} \mathrm{C}$. Separate samples were cycled between: (a) $U^{n} \leftrightarrow 150^{\circ} \mathrm{C}$, allu (b) $0^{\circ} \rightarrow 250^{\circ} \mathrm{C}$. The lsullesulal holds woru midiray of thr. first cycle. Tlie following cyoles followed the normal procedure.

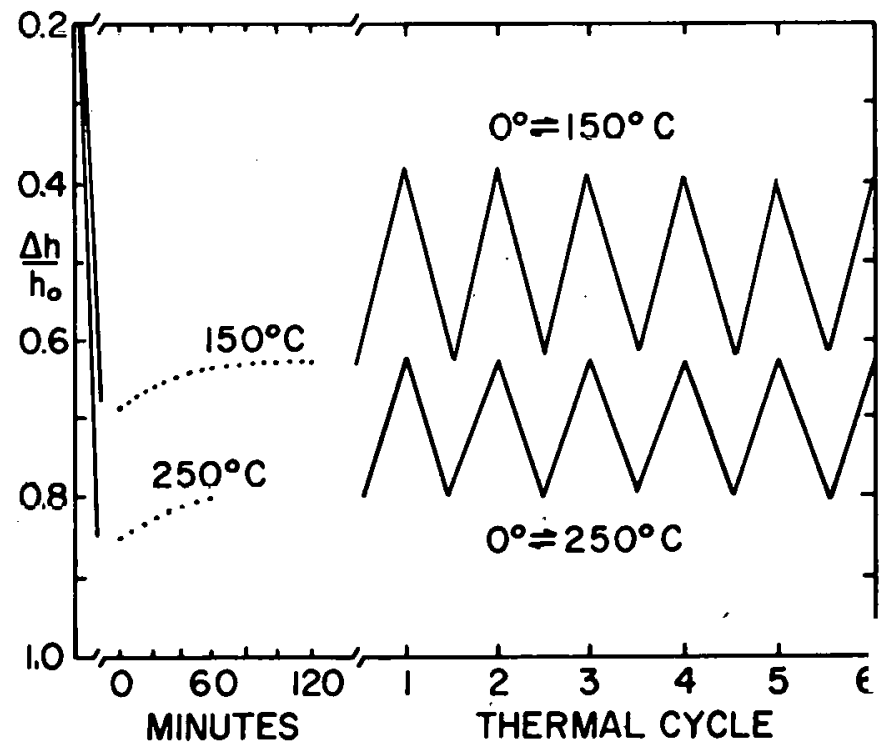


the magnitude of the reversible dimensional change. Further, re loss in reversibility increases as the holding temperature ulcreases.

The isothermal effect is also illustrated in Figure 2. The sample cycled from $0^{\circ} \leftrightarrow 375^{\circ} \mathrm{C}$ showed a decreasing shape change with each cycle. By the sixth cycle the shape change was practically nonexistent. Figure 5 shows a similar behavior in the $0^{\circ} \leftrightarrow 350^{\circ} \mathrm{C}$ and $0^{\circ} \leftrightarrow 400^{\circ} \mathrm{C}$ cycle. On heating to higher temperatures (i.e., above $290^{\circ} \mathrm{C}$ ), it took about 5 minutes for the sample to reach thermal equilibrium. This was a considerably longer time than for the vil bath used below $290^{\circ} \mathrm{C}$ and should be considered in comparing the curves.

Figure 5. Temperature-Induced Shape Change of the U-15 Atomic \% Nb Alloy. Only one sample was used. The subzero cycles were completed first and then successively higher cycling temperatures were achieved on the one sample.

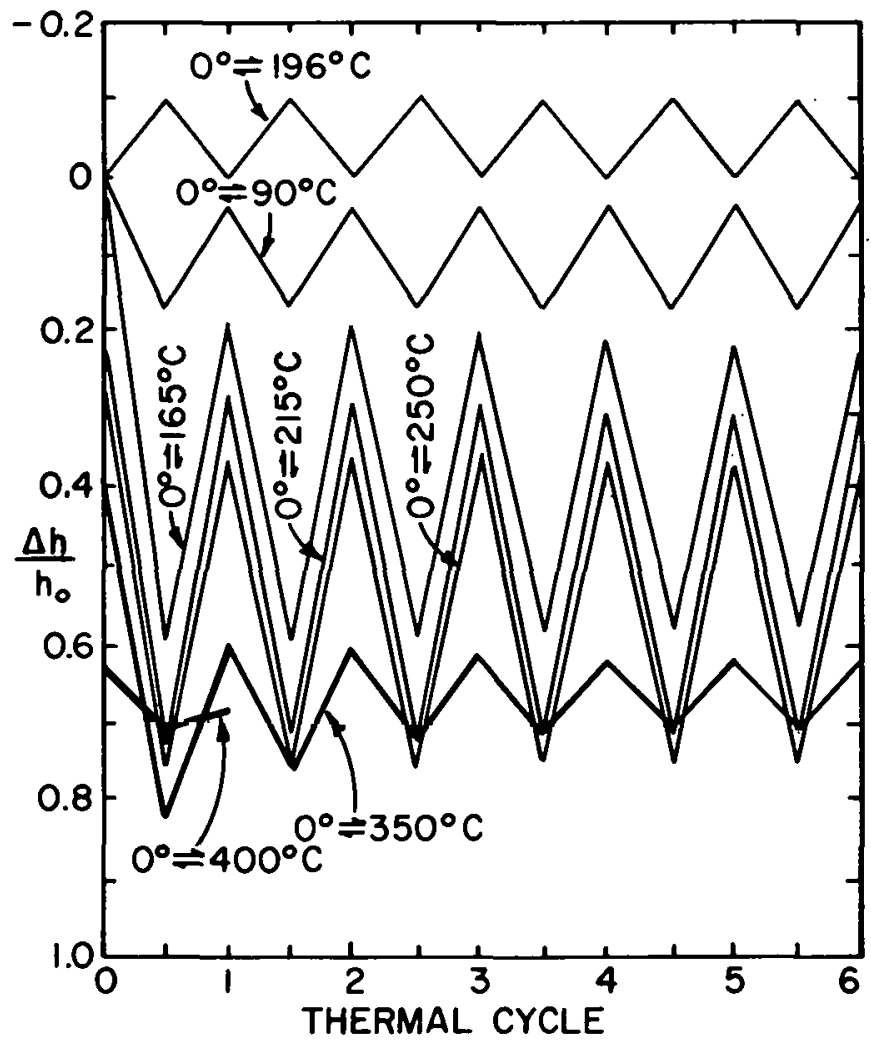

The isothermal effect, or at least a cycling effect, can also be seen at the lower temperatures. On cycling from $0^{\circ} \leftrightarrow 250^{\circ} \mathrm{C}$ there is a small but easily measured decrease in dimensional change with each cycle. This effect is partially the result of a slight warming of the low-temperature bath and cooling of the highemperature bath on rapid cycling. However, a correction -or this effect would account for, at most, only onethird of the irreversibility.
The effect that lower temperature cycling has on cycling at a higher temperature is shown in Figure 5. This figure shows the temperature-induced strain of the U-15 atomic \% $\mathrm{Nb}$ alloy on cycling the same specimen in the following sequence: (a) $0^{\circ} \mathrm{C} \leftrightarrow-196^{\circ} \mathrm{C}$, (b) $0^{\circ} \mathrm{C} \leftrightarrow 90^{\circ} \mathrm{C}$, (c) $0^{\circ} \mathrm{C} \leftrightarrow 165^{\circ} \mathrm{C}$, (d) $0^{\circ} \mathrm{C} \leftrightarrow 215^{\circ} \mathrm{C}$, (e) $0^{\circ} \mathrm{C} \leftrightarrow 250^{\circ} \mathrm{C}$, (f) $0^{\circ} \mathrm{C} \leftrightarrow 350^{\circ} \mathrm{C}$, and (g) $0^{\circ} \mathrm{C} \leftrightarrow 400^{\circ} \mathrm{C}$. There were six cycles at each temperature interval except the last one. When these data are compared with those of Figure 2, it is seen that the lower temperature cycles do appear to have an effect on cycling to a higher temperature. Prior lowtemperature cycling appears to cause an increase in the reversible portion of the shape change observed during subsequent high-temperature cycling.

\section{Additional Observations:}

Additional observations concerning temperature-induced shape changes associated with a bending deformation are:

1. The effect of quenching rate on magnitude of shape change was investigated. A U-15. atomic \% Nb alloy was air quenched from $850^{\circ} \mathrm{C}$, and then plastically bent in the normal manner. Subsequent dilatometric analysis between $0^{\circ} \mathrm{C}$ and $150^{\circ} \mathrm{C}$ showed a behavior similar to the water-quenched sample. However, the magnitude of the change was only about one-half that of the water quenched sample. Thus, the cooling rate from the gamma region has a distinct effect on the magnitude of shape change on subsequent thermal cycling.

2. Plastic deformation of the quenched shape is necessary for subsequent motion on thermal cycling. Non-deformed quenched samples did not show any motion on thermal cycling in the range $-200^{\circ} \mathrm{C}$ to $400^{\circ} \mathrm{C}$. The effect of bending prior to quenching was alsn examined. A U-15 atomic \% Nb alloy was bent at room temperature in the normal manner. This sample was mounted in a jig to maintain this shape, heated to $850^{\circ} \mathrm{C}$, and subsequently water quenched. The sample was then subjected to dilatometric analysis on thermal cycling in the normal manner. No motion of the sample was observed. Thus, plastic deformation of the quenched shape is required for the motion observed during subsequent thermal cycling.

3. Non-uniform plastic deformations give rise to residual stresses, and these can cause shape changes with changes in time and temperature. Thus, it was desirable to see if a significant macroresidual stress pattern existed in the bend specimens that exhibited temperature-induced strain. A previously water-quenched U-15 atomic \% $\mathrm{Nb}$ specimen 
was bent in the normal manner. Material was continually removed from the extension side of the bend by electropolishing until only the contraction side remained. During electropolishing, the specimen was free to move and no change in curvature occurred. Thus, it is concluded that the temperature-induced motion is not due to a macro-residual stress.

4. The memory for the as-quenched shape exhibited on heating is remarkable in that cyclic and unusual bending patterns will not fool the material as long as deformations are not too severe. Experiments confirming this statement are: (a) samples cyclically bent many times always showed a temperature-induced motion upon heating in the direction of the as-quenched shape; (b) samples bent into complex shapes always showed temperature-induced motion towards the as-quenched shape; and (c) as-quenched flat plates that were subsequiently cupped and then sectioned, would, upon heating, return toward the as-quenched shape.

\section{SHAPE MEMORY AFTER UNIAXIALLY INDUCED TENSILE AND COMPRESSIVE STRAINS; AND ROLLING STRAINS}

The question arises as to whether or not the temperatureinduced shape change is peculiar to a bending-induced strain. Would any type of plastic deformation give rise to shape changes on a subsequent heating and cooling? Three other means of inducing the plastic deformation were investigated, these were: (a) uniaxially applied tension, (b) uniaxially applied compression, and (c) cold rolling.

The quenching dilatometer used in these studies consisted of a perforated, fused-quartz outertube in which the sample set vertically. A vertical, fused-quartz push-rod rested on the sample. Connected to the push rod and the portable stand was a 0.1 -inch strain-gauge extensometer. The strain-gauge output was amplified and recorded using an Instron Model TTDL testing unit. The homemade, portable, quenching dilatometer coupled with the Instron strain-gauge extensometer system proved to be a stable and sensitive unit.

Figure 6 shows the temperature-induced shape-change behavior of a uniaxially compressed sample and a uniaxially stretched sample. The compression sample was a right cylinder 0.50 -inch long by 0.40 -inch diameter. This sample was water quenched from $850^{\circ} \mathrm{C}$, and subjected to three subzero cycles $\left(23^{\circ} \mathrm{C} \leftrightarrow-196^{\circ} \mathrm{C}\right)$

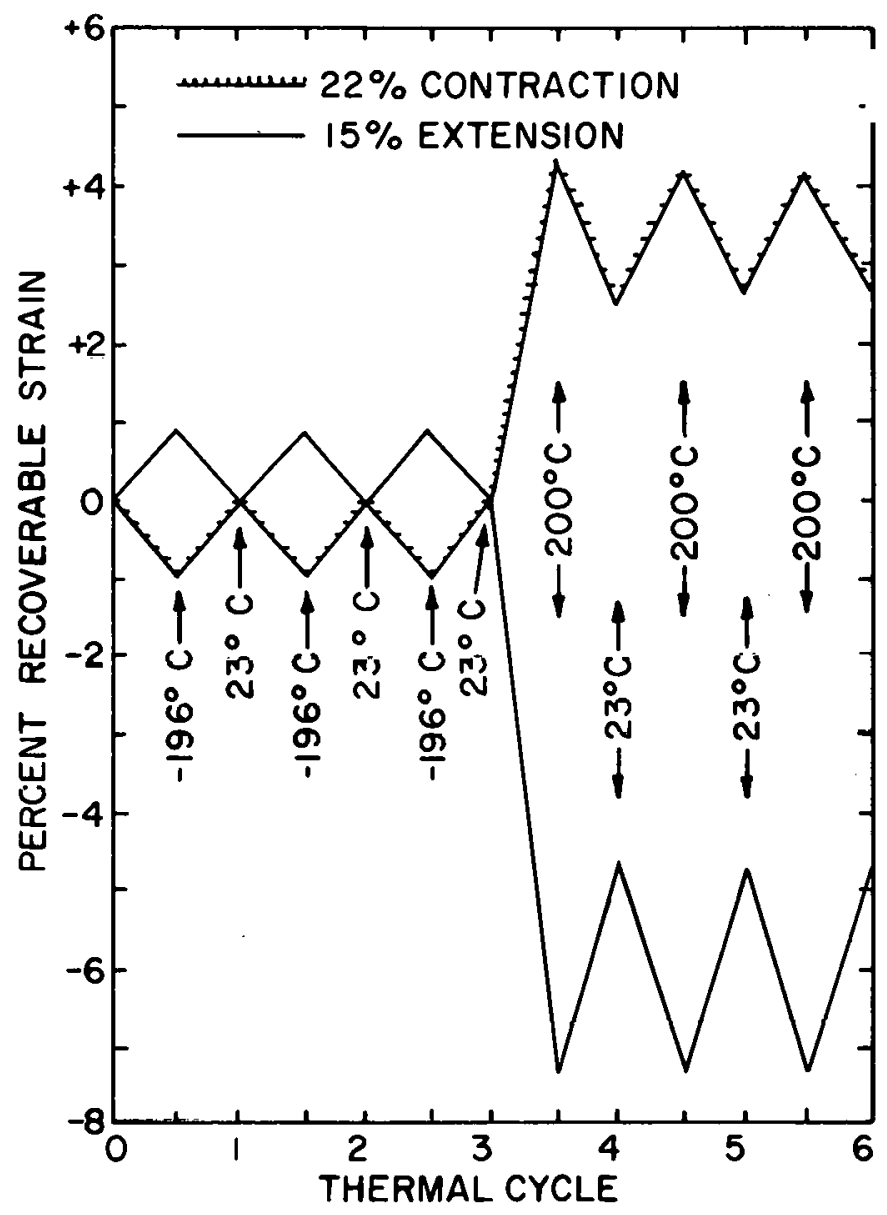

Figure 6. The Temperature-Induced Shape Change of a U.15 Atomic \% Nb Alloy Following a UniaxiallyInduced Compressive Strain (Dotted Solid Line) and a Uniaxially-Induced Tensile Strain (solid Line).

and three elevated temperature cycles $\left(23^{\circ} \mathrm{C} \leftrightarrow 200^{\circ} \mathrm{C}\right)$ using the quenching dilatometer. This same sample was then water quenched from $850^{\circ} \mathrm{C}$, uniaxially compressed (resulting in a permanent $22 \%$ decrease in length), and thcrmally cycled in the same manner as above using the quenching dilatometer. The dilatometric changes of the nondeformed state were subtracted from those of the plastically deformed state, and this difference is plotted in Figure 6.

The extension sample was a water-quenched flat bar 2.00 -in by 0.375 -in by 0.061 - inch. The extension sample in the nondeformed state was dilatometrically analyzed in the same manner as the compression sample. This sample was then water quenched from $850^{\circ} \mathrm{C}$, and given a $15 \%$ uniform plastic elongation over a one-inch gauge length at a strain rate of $0.02 \mathrm{in} . /$ in./minute. The extended gauge length section was removed and 
dilatometrically analyzed in the same manner as the londeformed state. The percent dialtometric changes of the nondeformed state was subtracted from those of the plastically deformed state and the difference is plotted in Figure 6.

Figure 6 shows the compression sample to expand un heding and contract on cooling, whereas the extension sample behaves in an opposite manner; that is, it contracts on heating and expands on cooling. This is, of course, the same behavior that occurs in the tension and compression regions of a bend specimen. Thus, one can conclude that either uniaxially induced tensile or.compressive plastic strains give rise to the temperature-induced, shapechange behavior.

In a similar experiment, two tensile test bars of the $\mathrm{U}-15$ atonic \% $\mathrm{Nb}$ alloy were prepared, then held 2 hours at $850^{\circ} \mathrm{C}$ and water quenched. The bars were given a $14 \%$ and $11 \%$ uniform plastic elongation, respectively, over a one-inch gauge length at a strain. rate of $0.02 \mathrm{in./in./} \mathrm{minute.} \mathrm{The} \mathrm{gauge} \mathrm{length} \mathrm{section}$ was then removed and measured. The sample given a $14 \%$ uniform elongation was heated 10 minutes at $350^{\circ} \mathrm{C}$ and was then rapidly cooled to $23^{\circ} \mathrm{C}$.

Remeasurement showed that $11 \%$ of the longitudinal cxtcnsion and lateral contraction that uccurred under uniaxial tension had been permanently recovered on heating to $350^{\circ} \mathrm{C}$.

The sample that was given an $11 \%$ uniform elongation was heated to $400^{\circ} \mathrm{C}$ and held for 10 minutes and was then rapidly cooled to $23^{\circ} \mathrm{C}$. Remeasurement showed that $16 \%$ of the initial longitudinal plastic extension had been permanently recovered during the subsequent thermal treatment. Thus, both samples given uniform elongations exhibited irreversible shape changes on thermal cycling in the same manner as the previously discussed bend specimens.
To test the effect of a cold deformation induced by rolling, a previously water-quenched 2.00 in long, $\mathrm{U}-15$ atomic $\% \mathrm{Nb}$ specimen was extended in length to 2.50 inches by cold rolling in one pass. Dilatometric analysis showed that on heating to $200^{\circ} \mathrm{C}$, the specimen decreased 20 mils in length (4\% of the extension induced by rolling) and recovered $8 \mathrm{mils}$ on cooling to the rolling temperature $\left(23^{\circ} \mathrm{C}\right)$. The 8 -mil longitudinal-length change was dimensionally reversible on continued thermal cycling between $23^{\circ} \mathrm{C}$ and $200^{\circ} \mathrm{C}$. Thus, the three means of plastic deformation discussed in this section, all give rise to a shape change behavior similar to that observed after a bending deformation.

\section{REFERENCES}

1. M.W. Burkart and T.A. Read, Trans. Met. Soc. AIME, . J. Metals, 197 (1953) 1516.

2. Z.S. Basinski and J.W. Christian, Acta Met., 2 (1954) 1.01 .

3. L.C. Chang and T.A. Read, Trans. Met. Soc. AIME, J. Merals, 189 (1951) 47.

4. D.S. Liberman, M.S. Wechsler, and T.A. Read, J. Appl. Phys., 26 (1955) 473.

5. W.J. Buehler, J.V. Gilfrich and R.C. Wiley, J. Appl. Phys., 34 (1963) 1475.

6. R.G..DeLange and J.A. Zijderveld, J.Appl. Phys, 39 (1968) 2195.

7. R. J. Jackson and D.V. Miley, ASM Trans. Quart.,61 (June 1968) 336. 